\title{
A PEJOTIZAÇÃO DO CONTRATO DE TRABALHO E A REFORMA
}

\author{
TRABALHISTA
}

\author{
José Antonio Remedio* \\ Selma Lúcia Doná**
}

\begin{abstract}
RESUMO: A pesquisa objetiva discutir a pejotização, que se apresenta pela contratação de trabalhador pessoa física na condição de pessoa jurídica, fenômeno bastante recente nas relações de trabalho e emprego, bem como analisar a possibilidade de contratação da pessoa jurídica à luz de algumas alterações normativas trazidas pela Lei 13.467/2017, conhecida como Reforma Trabalhista. O método adotado é o dedutivo, com base na doutrina, legislação e jurisprudência. Conclui que a pejotização, embora restrinja direitos historicamente assegurados no âmbito do Direito do Trabalho, é uma realidade no Brasil, e que a Lei 13.467/2017 permite a contratação de pessoas jurídicas na esfera trabalhista.
\end{abstract}

Palavras-chave: Flexibilização das Relações de Trabalho; Pejotização; Relação de Emprego; Relação de Trabalho; Reforma Trabalhista.

\section{THE PEJOTIZAÇÃO OF THE WORK CONTRACT AND THE LABOR LAWS REFORM}

\begin{abstract}
The research aims to discuss the "pejotization", a term that represents the hiring of individual as a legal entity, a recent phenomenon in the work and employment relation, and analyze the possibility of hiring a legal entity in the light of some amendments brought by Law 13.467/2017, known as the Labor Laws Reform. The method used is the deductive, based on doctrine, legislation and jurisprudence. In conclusion, the "pejotization", although it restricts the historically assured rights regarding the Labor Law, it is a reality in Brazil, and the Law $13.467 / 2017$ allows the employment of legal entities in the labor sphere.
\end{abstract}

Keywords: Easing of the Employment Relations; Pejotization; Employment Relation; Work Relation; Labor Laws Reform.

\footnotetext{
* Pós-Doutorando em Direito pela Universidade Estadual do Norte do Paraná (UENP). Doutor em Direito do Estado pela Pontifícia Universidade Católica de São Paulo (PUCSP). Professor de Graduação e Pós-graduação (Mestrado) em Direito da Universidade Metodista de Piracicaba (UNIMEP). Professor de Graduação em Direito do Centro Universitário Adventista de São Paulo (UNASP). Promotor de Justiça do Ministério Público do Estado de São Paulo Aposentado. Advogado. E-mail: jaremedio@yahoo.com.br

${ }^{* *}$ Mestranda em Direito pela UNIMEP. Especialista em Direito pela Escola Superior de Advocacia da Ordem dos Advogados do Brasil. Professora de Direito da UNIP. Advogada. Consultora Jurídica. E-mail: selma.dona@terra.com.br
} 


\section{INTRODUÇÃO}

A globalização e as transformações dela advindas no universo do trabalho vêm provocando muitas discussões ao longo das últimas décadas, em razão da busca de meios de flexibilização das relações de emprego através da terceirização e das diversas formas por ela empregadas, como a criação de cooperativas e a pejotização, principalmente em virtude da precarização nas relações de trabalho que revelam.

O estudo tem o objetivo de apresentar algumas ideias a respeito das mudanças trazidas pela Lei 13.467/2017, a chamada Reforma Trabalhista, e de sua influência na denominada pejotização, instituto que se apresenta pela contratação do trabalhador pessoa física, na condição de pessoa jurídica.

O tema se justifica na medida em que a discussão sobre a pejotização atinge atualmente muitos trabalhadores, e as alterações trazidas pela Reforma Trabalhista, embora não estejam direta e especificamente relacionadas ao tema, podem influenciar o atual entendimento a respeito da matéria.

A pesquisa baseia-se no método dedutivo, por meio da análise de bibliografia especializada, legislação e jurisprudência, com abordagem descritiva, buscando os conceitos vigentes as alterações provocadas pela legislação, estabelecendo correlações entre essas mudanças e os conceitos apresentados.

O trabalho foi estruturado enfocando os direitos humanos e o Direito do Trabalho, as relações de trabalho e emprego, a flexibilização das relações de trabalho, incluindo a pejotização e, finalmente, algumas disposições normativas alteradas pela Reforma Trabalhista que podem influenciar em uma mudança no entendimento do conceito atual e dos contornos da pejotização.

Tem-se, como hipótese, que a pejotização, embora em princípio restrinja direitos do trabalhador historicamente assegurados, é uma realidade no Brasil, e que a Lei 13.467/2017, que trata da Reforma Trabalhista, permite a contratação de pessoa jurídica no âmbito das relações de trabalho. 


\section{OS DIREITOS HUMANOS E O DIREITO DO TRABALHO}

A doutrina não é pacífica a respeito da definição e dos contornos dos denominados direitos humanos, inclusive em face da existência de diversas outras expressões com conteúdos próximos.

É bastante difícil definir um conceito sintético e preciso a respeito dos direitos fundamentais do homem, em razão do desenvolver da história, da ampliação e da transformação desses direitos.

O fato de se empregar diversas expressões para designarem os direitos fundamentais, tais como "direitos naturais, direitos humanos, direitos do homem, direitos individuais, direitos públicos subjetivos, liberdades públicas e direitos fundamentais do homem", aumenta ainda mais a dificuldade de sua definição (SILVA, 2014, p. 177).

Na opinião de Ricardo Castilho (2017, p. 202), a expressão “direitos humanos” tem sido utilizada para indicar o conjunto de direitos do homem positivado no âmbito internacional, através de declarações, tratados e outros instrumentos. De outro lado, a expressão "direitos fundamentais" seria utilizada para designar aqueles direitos internamente constitucionalizados pelo Estado.

A influência do tempo e da história tem desenhado novos contornos e provocado diversas mudanças, seja em relação aos direitos humanos, seja no tocante aos direitos fundamentais.

Na ótica de Norberto Bobbio (2004, p. 18), "os direitos do homem constituem uma classe variável, como a história destes últimos séculos demonstra suficientemente”. Para o autor, "o elenco dos direitos do homem se modificou, e continua se modificando, com a mudança das condições históricas, ou seja, dos carecimentos e dos interesses, das classes no poder, dos meios disponíveis para a realização dos mesmos, das transformações técnicas, etc.”.

Os direitos humanos e as garantias individuais destinam-se a estabelecer prerrogativas inerentes à dignidade da pessoa humana acima do poder de deliberação dos órgãos do Estado, evitando que políticas ocasionais coloquem em risco sua proteção e tutela (BRANDÃO, 2008, p. 452).

Esse, inclusive, é o comando contido no texto constitucional de 1988, que no artigo $1^{\circ}$, inciso III, prevê a dignidade da pessoa humana como um dos fundamentos da República Federativa do Brasil. 
No tocante a esse fundamento, anota Pedro Paulo Teixeira Manus (2011, p. 47) que o respeito à cidadania é elevado ao patamar de princípio fundamental, considerando que a dignidade da pessoa humana "é o conjunto de valores imateriais inerente a cada um de nós e cujo respeito pelo Estado e pela sociedade constituem a base da vida democrática", assegurando o exercício dos direitos sociais, direito ao trabalho, ao lazer e demais garantias sociais, respeitando os valores éticos e morais inerentes a todo cidadão.

Considerando que para se atingir a dignidade da pessoa humana é necessário assegurar certos direitos, alguns doutrinadores asseveram que o Direito ao Trabalho se identifica como um direito fundamental (GOMES, 2008, p. 928).

A dignidade da pessoa humana concede unidade aos direitos e garantias fundamentais, e pode ser enfocada como (MORAES, 2010, p. 22):

um valor espiritual e moral inerente à pessoa, que se manifesta singularmente na autodeterminação consciente e responsável da própria vida e que traz consigo a pretensão ao respeito por parte das demais pessoas, constituindo-se um mínimo invulnerável que todo estatuto jurídico deve assegurar, de modo que, somente excepcionalmente, possam ser feitas limitações ao exercício dos direitos fundamentais, mas sempre sem "menosprezar a necessária estima que merecem todas as pessoas enquanto seres humanos".

O Direito do Trabalho, por sua vez, pode ser visto como "o ramo da ciência do direito que tem por objeto as normas jurídicas que disciplinam as relações de trabalho por elas indicadas, determinam os seus sujeitos e as organizações destinadas à sua proteção, em sua estrutura e atividade" (NASCIMENTO, 2013, p. 317).

É certo que não é possível entender o Direito do Trabalho sem assimilar e compreender sua evolução, sendo necessária, mesmo que rápida, a análise da trajetória do Direito do Trabalho, perpassando sua transformação ao longo do tempo e da história.

Sergio Pinto Martins (2014, p. 4-6) ensina que, historicamente, na Bíblia, o trabalho era considerado um castigo, já que Adão foi obrigado a trabalhar por ter comido o fruto proibido. A escravidão foi a primeira forma de trabalho. Na época do feudalismo existiu a servidão, onde os senhores feudais, em troca do trabalho, davam proteção aos servos. Após o séc. XIV surgiram as corporações de ofício, onde existiam os mestres (proprietários das oficinais), os companheiros (trabalhadores que recebiam salários) e os aprendizes (menores que aprendiam com os mestres). As corporações foram suprimidas com a Revolução Francesa em 1789, que deu início à liberdade contratual, reconhecendo o direito ao trabalho. No século XVIII o 
liberalismo pregava o Estado alheio à área econômica. Com a Revolução Industrial, o trabalho foi transformado em emprego, passando os trabalhadores a trabalhar por salários.

Essa transformação do trabalho e o reconhecimento da necessidade da criação de direitos ao longo da história foram provocando inúmeras mudanças, em especial em relação às relações laborais.

A exemplo disso, a Declaração Americana dos Direitos e Deveres do Homem, aprovada na Nona Conferência Internacional Americana ocorrida em Bogotá em 1948, destaca o direito ao trabalho em seu artigo 14, e o dever ao trabalho em seu artigo 37, nos seguintes termos (DECLARAÇÃO, 1948):

Direito ao trabalho e a uma justa retribuição.

Artigo XIV. Toda pessoa tem direito ao trabalho em condições dignas e o de seguir livremente sua vocação, na medida em que for permitido pelas oportunidades de emprego existentes.

Toda pessoa que trabalha tem o direito de receber uma remuneração que, em relação à sua capacidade de trabalho e habilidade, lhe garanta um nível de vida conveniente para si mesma e para sua família.

$[\ldots]$

Dever do trabalho.

Artigo XXXVII. Toda pessoa tem o dever de trabalhar, dentro das suas capacidades e possibilidades, a fim de obter os recursos para a sua subsistência ou em benefício da coletividade.

Platon Teixeira de Azevedo Neto (2015, p. 39) afirma que o Direito do Trabalho surgiu no século XIX, num mundo "marcado pela desigualdade econômica e social, fenômeno que tornou necessária a intervenção do Estado por meio de uma legislação predominantemente imperativa, de força cogente, insuscetível de renúncia pelas partes”.

Todavia, não se pode perder de vista que, nas palavras de Rui Décio Martins, "desde tempo imemoráveis a humanidade busca regulamentar as relações de trabalho para torná-las mais dignas e erradicar a exploração de uns poucos sobre muitos, esbarrando seja no poder econômico como no político" (2012, p. 245).

Em um contexto de grandes transformações, as intervenções do Estado na autonomia individual tiveram, e ainda têm, como forma de garantir a dignidade da pessoa humana, a finalidade de trazer o "o reequilíbrio dos relacionamentos sociais nos quais um dos participantes está em nítida desvantagem (jurídica e/ou material) em face do outro” (GOMES, 2008, p. 932).

Na perspectiva da constitucionalização do Direito do Trabalho, o princípio da dignidade da pessoa humana previsto no inciso III do art. $1^{\circ}$ da Constituição Federal, constitui um dos fundamentos do direito laboral, e somente ocorrerá a efetivação deste princípio com o devido 
cumprimento dos direitos fundamentais nas relações laborais, de forma que o trabalhador não pode ser considerado um objeto de um contrato, e sim um sujeito, ser humano, cidadão detentor de todos os direitos fundamentais (REMEDIO; MARTINS, 2017, p. 286-287).

Entre os princípios constitucionais aplicáveis ao Direito do Trabalho destacam-se o princípio dos valores sociais do trabalho $\left(\mathrm{CF}\right.$, art. $\left.1^{\circ}, \mathrm{IV}\right)$, o princípio da justiça social $(\mathrm{CF}$, art. $1^{\circ}$, IV, e art. $3^{\circ}$, I e III) e o princípio da função social da propriedade e da ordem econômica (CF, arts. $5^{\circ}$, XXIII, 182, 184, 186 e 170, II e III) (REMEDIO, 2017, p. 78).

E, consoante entendimento do Tribunal Superior do Trabalho, acolhido quando do julgamento do Recurso de Revista n. 251-98.2012.5.12.0014, no âmbito do Direito do Trabalho vigoram preceitos imperativos de ordem pública, visando o amparo do trabalhador e a prevalência do princípio da justiça social, principalmente no que se refere às condições mínimas de trabalho (BRASIL, 2014).

\section{RELAÇÃO DE TRABALHO E RELAÇÃO DE EMPREGO}

Segundo Sadi Dal Rosso (2017, p. 71), "toda atividade humana realizada para transformar a natureza e o universo com vistas a desenvolver a vida é trabalho, realizado dentro das condições insubstituíveis de tempo, espaço, tecnologias e relações sociais".

Todavia, embora as expressões "relação de trabalho" e "relação de emprego" possuam sentidos próximos, nem toda relação de trabalho é relação de emprego, havendo inúmeras formas de trabalho que não possuem características de emprego.

A Emenda Constitucional 45/2004 alterou substancialmente a legislação trabalhista, ao ampliar a competência material da Justiça do Trabalho, tornando-a competente para processar e julgar tanto as ações oriundas das relações de trabalho como as decorrentes da relação de emprego (CF, art. 114, I).

Para esse estudo é importante fazer a distinção da relação de trabalho e de emprego, eis que as obrigações relativas ao contrato de trabalho subordinado, tais como registro em carteira, FGTS e férias, não alcançam as demais formas de contratos e prestações de serviços.

Nesse sentido, de acordo com Maria Amélia Lira de Carvalho (2010, p. 65):

A importância de compreender e distinguir o contrato de trabalho do contrato de prestação de serviço é maior quando é sabido que o Direito do Trabalho só assegura proteção aos sujeitos de uma relação de emprego. Os que trabalham por obrigação decorrente de sociedade não desfrutam das prerrogativas 
outorgadas por essa legislação, o que não significa que tais formas também não estejam sujeitas a proteção do direito.

A relação de trabalho alcança um sentido mais amplo que a relação de emprego, abrangendo todas as formas de trabalho, seja a de autônomo, voluntariado, cooperado, estatutário, sócios quotistas, parceiros e meeiros, dentre tantas outras atividades de trabalho que passam longe do emprego propriamente dito (SILVA, 2009, p. 6).

Consoante Maurício Godinho Delgado (2006, p. 285), a relação de trabalho tem caráter genérico e refere-se a toda modalidade de contratação de trabalho humano, englobando, inclusive, a relação de emprego.

Em relação ao caráter genérico da relação de trabalho, cumpre trazer alguns conceitos, como os relativos ao trabalho autônomo, avulso, de estágio e voluntário.

No tocante ao trabalho autônomo, Vólia Bomfim Cassar e Leonardo Dias Borges (2017, p. 44) analisam que:

\begin{abstract}
Autônomo é a pessoa física que trabalha habitualmente explorando seu oficio ou profissão por sua conta e risco. Normalmente tem clientela diversificada, mas não obsta que trabalhe para um único tomador, apesar de incomum. Sua liberdade e autonomia o diferenciam do empregado, que é subordinado. Além disso, o empregado não sofre os riscos do seu trabalho, e o autônomo sim. Desta forma, o verdadeiro autônomo não é empregado.
\end{abstract}

O trabalhador avulso, na lição de Gustavo Filipe Barbosa Garcia (2013, p. 273), caracteriza-se por prestar serviços a diversas empresas (sem fixação a uma fonte pagadora), com intermediação do sindicato ao órgão de Gestão de Mão de Obra”.

O trabalho do estagiário é regulado pela Lei 11.788/2008, que traz, em seu artigo $1^{\circ}$, o conceito de estágio como sendo o trabalho produtivo de educandos que estejam frequentando o ensino regular em instituições de educação superior, de educação profissional, de ensino médio, da educação especial e dos anos finais do ensino fundamental, na modalidade profissional da educação de jovens e adultos.

O trabalho voluntário é aquele que não possui onerosidade, exercido sem o intuito de receber remuneração (GARCIA, 2013, p. 297).

Conforme mencionado, a relação de emprego é espécie do gênero de relação de trabalho. Segundo Nascimento, a relação de emprego é aquela relação onde há trabalho subordinado (2013, p. 155). 
Neste sentido, a Consolidação das Leis do Trabalho estabelece o conceito de empregado no $\operatorname{artigo} 3^{\circ}$, nos seguintes termos (BRASIL, 1943):

Art. $3^{\circ}$ - Considera-se empregado toda pessoa física que prestar serviços de natureza não eventual a empregador, sob a dependência deste e mediante salário.

Parágrafo único - Não haverá distinções relativas à espécie de emprego e à condição de trabalhador, nem entre o trabalho intelectual, técnico e manual.

A relação de emprego depende essencialmente da existência dos seguintes elementos fático-jurídicos: trabalho por pessoa física; pessoalidade; não-eventualidade; onerosidade e subordinação (DELGADO, 2006, p. 291).

Para descrever cada um dos elementos fático-jurídicos, Maurício Godinho Delgado (p. 291-298) ensina que o trabalho por pessoa física é aquele que é prestado pela pessoa natural do trabalhador. A pessoalidade é descrita como a impossibilidade do trabalhador se fazer substituir por outro na prestação dos serviços. A não eventualidade é caracterizada pelo trabalho prestado com caráter de permanência, de continuidade, não esporádico. Onerosidade é a relação empregatícia de fundo econômico, de modo que a força de trabalho do empregado deve corresponder a uma contraprestação econômica. Por fim, o requisito da subordinação é elemento essencial na distinção entre a relação de trabalho e emprego, podendo ser compreendida como a situação jurídica pela qual o empregado compromete-se a acolher o poder de direção empresarial no modo de realização de sua prestação de serviços.

Assim, as relações de trabalho possuem características variadas, cada qual com suas especificidades. Entretanto, a proteção legal recai com muito mais rigorismo e força sob a relação de emprego, em razão da hipossuficiência do trabalhador, da sua subordinação ao empregador e da superioridade econômica deste último.

\section{A FLEXIBILIZAÇÃO DAS RELAÇÕES DE TRABALHO E A PEJOTIZAÇÃO}

A globalização não é um fenômeno novo. As nações, desde as grandes conquistas, sempre influenciaram umas às outras, destacando as ações do Império Romano, impondo seus costumes e leis a seus conquistados, ou mesmo, durante o século XVI, a transformação dos usos e costumes da América do Sul, ocorrida através das conquistas pelos portugueses e espanhóis (MANUS, 2011, p. 111). 
O processo que a globalização desencadeia traz novos contornos aos contratos de trabalho, na medida em que alteram sua estrutura, através de redes de subcontratação, tornandoas mais flexíveis (ANTUNES; DRUCK, 2014, p. 14).

Sob esse aspecto, observa Leone Pereira (2015, p. 64) que:

A globalização da economia, e consequente aumento da competição, além da revolução tecnológica, determinam um intenso processo de alteração de paradigmas. No âmbito da gestão empresarial, a nova política industrial trabalha com a ideia de reestruturação de setores sujeitos à condição de competitividade, que consiste em produzir mais, com menos empregados.

O processo de flexibilização, por sua vez, encontra-se presente desde as três últimas décadas do Século XX em países capitalistas industrializados e, nos países de capitalismo recente, está presente através da informalidade e do desrespeito ao Direito do Trabalho (ROSSO, 2017, p. 10).

Pedro Paulo Teixeira Manus (2011, p. 111-112) verifica que, para essa mudança do enquadramento jurídico das formas de prestação de serviço, a doutrina tem adotado a expressão flexibilização e que esse fenômeno tem permitido soluções diversas das regras tradicionais do contrato de trabalho (2011, p. 111-112).

Ricardo Antunes e Graça Druck (2014, p. 13) destacam que o capitalismo nas décadas mais recentes tem sido substituído pelos modos mais distintos e diversificados de terceirização, informalidade - que deixa de ser exceção para tornar-se regra. Segundo os autores (2014, p. 17):

Assim, a terceirização assume centralidade na estratégia patronal, já que suas diversas modalidades (tais como cooperativas, pejotização, organizações não governamentais, além de redes de subcontratação) concretizam "contrato", ou forma de compra e venda da força de trabalho, em que as relações de trabalho sociais entre capital e trabalho são disfarçadas e travestidas de relações interempresas/instituições, além de estabelecer contratos por tempo determinado, flexíveis, de acordo com ritmos produtivos das empresas contratantes e as quase sempre imprevisíveis oscilações de mercado que desestruturam o trabalho, seu tempo e até mesmo sua sobrevivência.

Segundo Pedro Paulo Teixeira Manus (2011, p. 111-112), os Estados têm sido submetidos aos interesses econômicos multinacionais, que determinam a ação empresarial no mundo todo.

Muitas vezes esses processos de flexibilização são tidos "como objetos foscos, recobertos por camadas de pressupostos ideológicos e teóricos, de tal modo que se torna difícil 
interpretar seu significado". Em sua essência "escondem-se significados herméticos, donde procede a tarefa de compreender não apenas as manifestações concretas da flexibilidade como, inclusive, os pressupostos sobre os quais ela se firma" (ROSSO, 2017, p.12).

A Lei 13.467/2017, conhecida como Reforma Trabalhista, aborda aspectos da flexibilização das regras aplicáveis ao contrato de trabalho, rompendo com a lógica tradicional instaurada por meio da Consolidação das Leis do Trabalho e legislação correlata.

De acordo com Mauricio Godinho Delgado e Gabriela Neves Delgado (2017, p. 41-43), a Lei 13.467/2017 busca romper a "lógica civilizatória, democrática e inclusiva do Direito do Trabalho, por meio da desregulamentação ou flexibilização de suas regras imperativas incidentes sobre o contrato trabalhista", sendo essa "a marca e o sentido rigorosamente dominantes desse diploma legal no campo laborativo do Direito". Para os autores, a lei em questão implica num "manifesto desprezo à noção de centralidade da pessoa humana na ordem jurídica e na vida social”, no esvaziamento "do princípio constitucional da igualdade em sentido material no contexto das relações empregatícias", numa estratégia de desconstrução "do arcabouço normativo constitucional e infraconstitucional de proteção à saúde e segurança do trabalhador no âmbito das relações trabalhistas", na tentativa "de driblar as normas jurídicas de inclusão de pessoas humanas vulneráveis no mercado de trabalho", na exacerbação da duração do trabalho em todo o mercado laborativo" e na "descaracterização da natureza salarial de parcelas pagas ao empregado no contexto da relação de emprego" .

Ao lado das demais formas de flexibilização, o fenômeno da pejotização tem sido discutido com bastante frequência nos últimos anos. Trata-se de modalidade onde uma empresa, ou pessoa jurídica (PJ) é constituída para a prestação de serviços, com contornos e características de relação de emprego.

A respeito da pejotização, Maria Amélia Lira de Carvalho (2010, p. 62) verifica que:

Sob o pretexto de modernização das relações de trabalho é que se insere uma das novas modalidades de flexibilização, que resulta na descaracterização do vínculo de emprego e que se constitui na contratação de sociedades (PJ) para substituir o contrato de emprego. São as empresas do "eu sozinho" ou "PJs" ou "pejotização" como comumente vêm sendo denominadas.

Segundo Leone Pereira (2015, p. 77), “conceitua-se pejotização como a contratação de um trabalhador na condição de pessoa jurídica, para a prestação de serviço intelectual”, sendo que sua viabilidade foi introduzida pela Lei 11.196/2005.

Nos termos do art. 129 da Lei 11.196/2005 (BRASIL, 2005): 
Para fins fiscais e previdenciários, a prestação de serviços intelectuais, inclusive os de natureza científica, artística ou cultural, em caráter personalíssimo ou não, com ou sem a designação de quaisquer obrigações a sócios ou empregados da sociedade prestadora de serviços, quando por esta realizada, se sujeita tão-somente à legislação aplicável às pessoas jurídicas, sem prejuízo da observância do disposto no art. 50 da Lei n ${ }^{\circ} 10.406$, de 10 de janeiro de 2002 - Código Civil.

A crescente utilização da pejotização tem sido considerada por parte expressiva da jurisprudência brasileira como meio de fraudar e precarizar as relações empregatícias e, em razão disso, são duramente combatidas pelos Tribunais Trabalhistas do país.

Nesse sentido, em 2018, o Tribunal Regional do Trabalho da $7^{\text {a }}$ Região, ao julgar o Recurso Ordinário n. 00013985820165070015, entendeu que (BRASIL, 2018a):

VÍNCULO DE EMPREGO RECONHECIDO. PEJOTIZAÇÃO. Evidenciada a fraude perpetrada pelo empregador ao condicionar a contratação de serviços inerentes à atividade finalística da empresa à constituição de pessoa jurídica pelo trabalhador (pejotização), o reconhecimento do vínculo empregatício é medida que se impõe.

Em 2017, o Tribunal Regional do Trabalho da $1^{\text {a }}$ Região, quando do julgamento do Recurso Ordinário n. 00109485820155010022-RJ, decidiu que (BRASIL, 2017):

VÍNCULO DE EMPREGO. PEJOTIZAÇÃO. FRAUDE À LEGISLAÇÃO TRABALHISTA. O fenômeno da "pejotização" consiste na constituição de pessoa jurídica com o escopo de mascarar verdadeira relação de emprego, em nítida fraude à legislação trabalhista (art. $9^{\circ}$ da CLT), com a supressão de direitos constitucionalmente assegurados (art. $7^{\circ}, \mathrm{CRFB}$ ), e violação dos princípios da dignidade humana (art. $1^{\circ}$, III, CRFB) e da valorização do trabalho (art. 170 e 193, CRFB). Sendo assim, comprovado nos autos que o autor foi empregado do réu, impõe-se o reconhecimento da fraude perpetrada pelo demandado e a formação do vínculo de emprego.

Em 2015, o Tribunal Regional do Trabalho da 2a Região, ao julgar o Recurso Ordinário n. 00000437620115020031, entendeu que (BRASIL, 2015):

RECURSO ORDINÁRIO. PEJOTIZAÇÃO. FRAUDE AOS PRECEITOS TRABALHISTAS. VÍNCULO EMPREGATÍCIO RECONHECIDO. Da análise de todo processado, resta induvidoso que houve a ocorrência do fenômeno da pejotização, que consiste na contratação de trabalhador por meio de empresa criada para mascarar o real liame jurídico entre as partes, no claro intuito de fraudar a legislação trabalhista. Implementados os requisitos da relação de emprego, ainda que escamoteados sob a forma simulada de contratos de prestação de serviços, o reconhecimento do vínculo empregatício é medida que se impõe. Apelo patronal desprovido no tema.

Rev. de Direito do Trabalho e Meio Ambiente do Trabalho | e-ISSN: 2525-9857 | Porto Alegre | v. 4 | n. 2 | p. 61 - 79 | Jul/Dez. 
Em 2011, o Tribunal Regional do Trabalho da $3^{\text {a }}$ Região, quando do julgamento do Recurso Ordinário n. 0001706-18.2010.5.03.0112, decidiu que (BRASIL, 2011):

EMPRESA CONSTITUÍDA PARA FRAUDAR A LEGISLAÇÃO TRABALHISTA - RELAÇÃO DE EMPREGO CONFIGURADA FENÔMENO DA PEJOTIZAÇÃO. A pejotização é o fenômeno pelo qual a criação de pessoas jurídicas é fomentada pelo tomador de serviços com o propósito de se esquivar das obrigações e encargos trabalhistas. Contudo, vigora no Direito do Trabalho o princípio da irrenunciabilidade, mediante o qual não é permitido às partes, ainda que por vontade própria, renunciar aos direitos trabalhistas inerentes à relação de emprego existente.

Por sua vez, o Tribunal Superior do Trabalho, quando do julgamento do Recurso de Revista n. 2632-58.2010.5.02.0069 em 2018, sufragou o entendimento no sentido de que a pejotização caracteriza burla à legislação trabalhista, nos termos do art. $9^{\circ}$ da Consolidação das Leis do Trabalho (BRASIL, 2018b).

Em síntese, as decisões judiciais acima transcritas, inclusive do Tribunal Superior do Trabalho, apontam a pejotização como fraude, ou seja, a constituição de pessoa jurídica, com o objetivo de esquivar-se do cumprimento de obrigações trabalhistas, mascarar a verdadeira relação de emprego e suprimir direitos constitucionalmente garantidos.

Todavia, não se nega que os negócios em geral são regidos por meio de regras do mercado, da oferta e da procura, o que tende a influenciar diretamente as relações de trabalho e de emprego.

Para Fabio Konder Comparato (2015, p. 566), “o capitalismo não é um mero sistema econômico, mas uma forma global de vida em sociedade; ou, se se quiser, dando ao termo um sentido neutro, uma civilização". Ainda para o autor, "nesse tipo de civilização, toda a vida social, e não apenas as relações econômicas, fundam-se na supremacia absoluta da razão de mercado".

E, como observa Sadi Dal Rosso (2017, p. 11), o "futuro do labor foi caracterizado como momento do trabalho flexível, ao passo que trabalho rígido descrevia o tempo passado".

As regras do mercado, entretanto, não podem servir de fundamento para a instituição e implementação de institutos que fraudem ou cerceiem os direitos dos trabalhadores, como ocorre em grande medida com a pejotização. 


\section{A INFLUÊNCIA DA REFORMA TRABALHISTA NA PEJOTIZAÇÃO}

As alterações advindas da Lei 13.467/2017, chamada Reforma Trabalhista, trazem grande impacto na legislação trabalhista anterior, na medida em que, além de modificar diversos textos normativos, acabam tanto ampliando como restringindo diversos direitos dos trabalhadores.

Sob esse aspecto, a Reforma Trabalhista trouxe variadas e substanciais alterações em artigos da Consolidação das Leis do Trabalho - CLT (Decreto-Lei 5.452/1943), da Lei 6.019/1974 (que dispõe sobre o trabalho temporário nas empresas urbanas), da Lei 8.036/1990 (que trata do Fundo de Garantia do Tempo de Serviço) e da Lei 8.212/1991 (que dispõe sobre a organização da Seguridade Social, a fim de adequar a legislação às novas relações de trabalho).

Importante esclarecer que várias questões trazidas pela Reforma Trabalhista foram objeto de anterior alteração por meio da Medida Provisória $n^{\circ}$ 808, de 14 de novembro de 2017. Porém, referida Medida Provisória teve seu prazo de vigência até 23 de abril de 2018, perdendo, portanto, sua eficácia a partir desta data.

Destacam-se a seguir alguns dos artigos trazidos pela Reforma Trabalhista, que podem ampliar as discussões acerca da pejotização, observando-se que o rol não é taxativo, pois podem surgir outras questões com a evolução da jurisprudência que se formará a partir dos novos julgados na órbita dos diversos Tribunais do país.

A alteração trazida pela Reforma Trabalhista no artigo 4-A da Lei 6.019/1974 permite a terceirização da atividade-fim. Nesse sentido, dispõe o referido texto normativo (BRASIL, 1974):

Art. $4^{\circ}$-A. Considera-se prestação de serviços a terceiros a transferência feita pela contratante da execução de quaisquer de suas atividades, inclusive sua atividade principal, à pessoa jurídica de direito privado prestadora de serviços que possua capacidade econômica compatível com a sua execução.

O art. $4^{\circ}$-A da Lei 6.019/1974 pode influenciar diretamente as discussões a respeito da pejotização, na medida em que a alteração normativa permitiu a terceirização da atividade principal, possibilitando a contratação de empresas para executar a atividade-fim da contratante. Ou seja, o que anteriormente era ilícito, tornou-se permitido pela nova legislação.

A introdução do artigo 442-B, pela Reforma Trabalhista, na Consolidação das Leis do Trabalho - Decreto-Lei 5.452/1943, também trouxe novidade, já que permite a exclusividade e 
a continuidade do trabalho prestado pelo autônomo. Assim, conforme dispõe o art. 442-B, "a contratação do autônomo, cumpridas por este todas as formalidades legais, com ou sem exclusividade, de forma contínua ou não, afasta a qualidade de empregado prevista no art. $3^{\circ}$ desta Consolidação" (BRASIL, 1943).

Os requisitos da exclusividade e continuidade, que antes eram exigidos para caracterizar o vínculo de emprego (juntamente com a onerosidade, pessoalidade e subordinação), foram integralmente afastados pela alteração da legislação no caso da prestação de serviços pelo autônomo.

A exclusividade da prestação de serviços e a habitualidade, aliadas à terceirização da atividade-fim, são requisitos comumente invocados para reconhecer o vínculo de emprego em casos de pejotização.

Nesse sentido, “o uso de PJ é lícito nos casos de contratação para prestação de serviços não habituais, não subordinados. Mas não quando pessoas são contratadas para exercer as atividades inerentes da empresa" (TURCATO; RODRIGUES, 2008, p. 11).

Outra novidade foi o arranjo trazido no parágrafo primeiro do artigo 444 da CLT, nos seguintes termos (BRASIL, 1943):

Art. 444 - As relações contratuais de trabalho podem ser objeto de livre estipulação das partes interessadas em tudo quanto não contravenha às disposições de proteção ao trabalho, aos contratos coletivos que lhes sejam aplicáveis e às decisões das autoridades competentes.

Parágrafo único. A livre estipulação a que se refere o caput deste artigo aplicase às hipóteses previstas no art. 611-A desta Consolidação, com a mesma eficácia legal e preponderância sobre os instrumentos coletivos, no caso de empregado portador de diploma de nível superior e que perceba salário mensal igual ou superior a duas vezes o limite máximo dos benefícios do Regime Geral de Previdência Social.

A respeito do referido parágrafo único, destacam Vólia Bomfim Cassar e Leonardo Dias Borges (2017, p. 47) que, uma vez cumpridos os requisitos (ter diploma de curso superior e percepção de salário acima do teto legal), os quais entende cumulativos, o empregado poderá renunciar aos direitos previstos nas normas coletivas, prevalecendo o ajuste individual de vontade das partes.

Alguns estudiosos nominaram os trabalhadores que firmarem acordo individual com base no parágrafo único do artigo 444 da CLT como trabalhadores autossuficientes (DUBRUGAS, 2018, p.155), outros nominaram-nos como empregados hipersuficientes (CORREIA; MIESSA, 2018, p.333). 
O cumprimento objetivo dos requisitos do diploma de curso superior e a percepção de salário acima do valor do teto colocam o empregado como autossuficiente a discutir diversos dos aspectos de seu contrato de trabalho diretamente com o empregador, inclusive sem a interferência ou intermediação sindical.

Acerca dos requisitos da autonomia trazida pela lei em questão, cumpre transcrever as palavras de Regina Maria Vasconcelos Dubugras (2018, p. 157):

\begin{abstract}
A análise da autonomia negocial do empregado deveria ser considerada no caso concreto, levando em conta a atividade, a capacidade de trabalho, a independência, as vantagens e conveniência para sua vida pessoal e as características do trabalho que desenvolve. O atributo da condição de hipossuficiência, utilizado tanto no sentido de dependência econômica como no sentido de baixo nível cultural, reflete a incapacidade negocial, contudo, este atributo há tempo já não pode ser mais generalizado, não sendo razoável assumir que toda concordância do empegado seja resultado de fraude praticada pelo empregador.
\end{abstract}

É certo que a ampliação que o art. 444 da Consolidação das Leis do Trabalho demonstra a possibilidade de considerar o trabalhador, que preenche tais requisitos, suficiente nas suas escolhas, sendo também certo que tal prerrogativa pode abrir uma porta para que, futuramente, o trabalhador tenha condições de decidir o meio pelo qual pretende ser contratado, afastando o entendimento de ocorrência de fraude em casos de pejotização.

Assim, as alterações trazidas pela Reforma Trabalhista poderão trazer novos contornos ao assunto, já bastante polêmico, que é a pejotização, demandando serem trazidas a lume novas discussões e, futuramente, como bem observa Leone Pereira (2015, p. 11), a edição de uma lei própria a respeito do tema, ou seja, a "Lei da Pejotização".

\title{
5. CONCLUSÃO
}

O fenômeno da globalização e as transformações dela decorrentes no universo do exercício da atividade laboral têm acarretado muitas discussões ao longo das últimas décadas, em razão da busca de meios de flexibilização das relações de emprego, através da terceirização da atividade trabalhista, destacando-se a criação de cooperativas e a pejotização.

A pejotização, modalidade onde uma empresa ou pessoa jurídica (PJ) é constituída para a prestação de serviços com contornos e características de relação de emprego, ao lado da flexibilização, tem sido discutida com bastante frequência nos últimos anos. 
A crescente utilização da pejotização, entretanto, tem sido considerada por parte expressiva da jurisprudência dos Tribunais Brasileiros como meio de fraudar e precarizar as relações empregatícias e, em razão disso, tem sido duramente combatida.

Assim, a jurisprudência, até o advento da Lei 13.467/2017, tem rechaçado a prática da pejotização, dando preferência ao reconhecimento da relação de emprego quando constatada a prestação dos serviços com subordinação, pessoalidade e onerosidade, a despeito da constituição formalmente regular da pessoa jurídica e da existência de contrato civil de prestação de serviços.

O estudo apresenta algumas ideias a respeito das mudanças trazidas pela Lei 13.467/2017, a chamada Reforma Trabalhista, e de sua influência na denominada pejotização, principalmente em razão da precarização que acarreta nas relações de trabalho.

A pejotização atinge atualmente muitos trabalhadores, e as alterações decorrentes da Reforma Trabalhista, embora não estejam direta e especificamente relacionadas com questão, acabam influenciando o entendimento a respeito da matéria.

Sob esse aspecto, a possibilidade de terceirização da atividade-fim no âmbito da relação trabalhista deixa de ser um impedimento à contratação pelas empresas.

$\mathrm{O}$ art. $4^{\circ}$-A da Lei 6.019/1974, trazido pela Reforma Constitucional, pode influenciar diretamente as discussões a respeito da pejotização, por permitir a terceirização da atividade principal, possibilitando a contratação de empresas para executar a atividade-fim da contratante.

O art. 443-B da Lei CLT, trazido pela Lei 13.467/2017, estatui que no trabalho autônomo deixa de haver impedimento de se prestarem serviços com exclusividade, podendo tais atividades serem exercidas de forma contínua, o que demonstra a intenção do legislador de flexibilizar as regras anteriores.

No tocante à introdução do parágrafo único do artigo 444 da Consolidação das Leis do Trabalho (BRASIL, 1943) pela Reforma Trabalhista, constata-se que este provocará uma modificação importante na interpretação das relações de trabalho, na medida em que ela permite renúncias por parte dos empregados que preencherem seus requisitos, quebrando o paradigma da hipossuficiência desses empregados e os tornando suficientes em suas decisões, o que pode alterar (a longo prazo) a lógica das prestações de serviços, permitindo que o trabalhador decida, entre o contrato com vínculo de emprego ou através de empresa (pessoa jurídica), sem que isso possa necessariamente caracterizar uma fraude.

Tem-se, em conclusão, que restou demonstrada a hipótese inicialmente apresentada, no sentido de que a pejotização, embora restrinja direitos do trabalhador historicamente 
assegurados, é uma realidade no Brasil, e que a Lei 13.467/2017, que trata da Reforma Trabalhista, permite a contratação de pessoa jurídica no âmbito das relações de trabalho.

\section{REFERÊNCIAS}

ANTUNES, Ricardo; DRUCK, Graça. A epidemia da terceirização. In: ANTUNES, Ricardo (Org.). Riqueza e miséria do trabalho no Brasil III. São Paulo: Boitempo, 2014.

AZEVEDO NETO, Platon Teixeira. O trabalho decente como um direito humano. São Paulo: LTr, 2015.

BOBBIO, Norberto. A Era dos direitos. Rio de Janeiro: Elsevier, 2004.

BRANDÃO, Rodrigo. São os direitos sociais cláusulas pétreas? Em que medida? In: SOUZA NETO, Cláudio Pereira; SARMENTO, Daniel (Coords.). Direitos sociais: fundamentos, judicialização, direitos sociais em espécie. Rio de Janeiro: Lumen Juris, 2008, p. 451-483.

BRASIL. Decreto-Lei $\mathrm{n}^{\mathrm{o}}$ 5.452, de $1^{\circ}$ de maio de 1943. Disponível em: http://www.planalto.gov.br/ccivil_03/Decreto-Lei/Del5452.htm. Acesso em 9 jul. 2018.

BRASIL. Lei $\mathrm{n}^{\circ}$ 6.019, de 3 de janeiro de 1974. Disponível em: <http://www.planalto .gov.br/ccivil_03/Leis/16019.htm>. Acesso em 19 jun. 2018.

Lei $\mathrm{n}^{\circ}$ 11.196, de 21 de novembro de 2005. Disponível em: <http://www. planalto.gov.br/ccivil_03/_ato2004-2006/2005/lei/111196.htm>. Acesso em 20 jun. 2018.

Tribunal Regional do Trabalho da $1^{\mathrm{a}}$ Região. Recurso Ordinário n. 00109485820155010022-RJ. Relatora Desembargadora Raquel de Oliveira. Julg. 2017. Disponível em: <https://trt-1.jusbrasil.com.br/jurisprudencia/509340235/recurso-ordinarioro-109485820155010022-rj>. Acesso em: 21 jun. 2018.

Tribunal Regional do Trabalho da $2^{\mathrm{a}}$ Região. Recurso Ordinário n. 00000437620115020031. Relator Desembargador Orlando Apuene Bertão. Julg. 2015. Disponível em: <https://trt-2.jusbrasil.com.br/jurisprudencia/312260343/recurso-ordinario-ro437620115020031-sp-00000437620115020031-a28>. Acesso em: 21 jun. 2018.

Tribunal Regional do Trabalho da $3^{\mathrm{a}}$ Região. Recurso Ordinário n. 000170618.2010.5.03.0112. Relator Desembargador Paulo Roberto Sifuentes Costa. Julg. 2011. Disponível em: <https://trt-3.jusbrasil.com.br/jurisprudencia/124308330/recurso-ordinariotrabalhista-ro-1706201011203000-0001706-1820105030112>. Acesso em: 21 jun. 2018.

. Tribunal Regional do Trabalho da $7^{\mathrm{a}}$ Região. Recurso Ordinário n. 00013985820165070015. Relator Francisco José Gomes da Silva. Julg. 2018a. Disponível em: $\quad$ https://trt-7.jusbrasil.com.br/jurisprudencia /561396348/recurso-ordinario-ro$13985820165070015>$. Acesso em: 22 jun. 2018.

Tribunal Superior do Trabalho. Recurso de Revista n. 251-98.2012.5.12.0014. Ministro Luiz Philippe Vieira de Mello Filho. Brasília: DEJT, 19 dez. 2014.

Tribunal Superior do Trabalho. Recurso de Revista n. 2632-58.2010.5.02.0069. Relator Ministro Cláudio Mascarenhas Brandão. Brasília, DEJT, 16 mar. 2018b. 
CARVAlho, Maria Amélia Lira de. Pejotização e descaracterização do contrato de emprego: o caso dos médicos em Salvador - Bahia. Dissertação (Mestrado em Políticas Sociais e Cidadania). Salvador: Universidade Católica de Salvador, UCSAL, 2010.

CASSAR, Vólia Bomfim; BORGES, Leonardo Dias. Comentários à reforma trabalhista. Rio de Janeiro: Forense; São Paulo: Método, 2017.

CASTILHO, Ricardo. Direitos humanos. 4. ed. São Paulo: Saraiva, 2017.

COMPARATO. Fabio Konder. A afirmação histórica dos direitos humanos. 10. ed. São Paulo: Saraiva, 2015.

CORREIA, Henrique; MIESSA, Élisson. Manual da reforma trabalhista: comentários artigo por artigo. Salvador: Juspodivm, 2017.

DECLARAÇÃO AMERICANA DOS DIREITOS E DEVERES DO HOMEM - 1948. Disponível em: https://www.cidh.oas.org/basicos/portugues/b.Declaracao_Americana.htm. Acesso em 10 jul. 2018.

DELGADO, Mauricio Godinho. Curso do direito do trabalho. 5. ed. São Paulo: LTr, 2006.

DELGADO; Mauricio Godinho; DELGADO, Gabriela Neves. A reforma trabalhista no Brasil: com comentários à Lei n. 13.467/2017. São Paulo: LTY, 2017.

DUBUGRAS, Regina Maria Vasconcelos. Acordo individual firmado com empregado autossuficiente - art. 444, parágrafo único, da CLT. Revista do Advogado da Associação dos Advogados de São Paulo - AASP, São Paulo, ano XXXVIII, n. 137, p. 155-159, mar. 2018.

GARCIA, Gustavo Filipe Barbosa. Curso de direito do trabalho. 7. ed. Rio de Janeiro: Forense, 2013.

GOMES, Fabio Rodrigues. O direito fundamental ao trabalho: uma miragem discursiva ou uma norma efetiva. In: SOUZA NETO, Cláudio Pereira; SARMENTO, Daniel (Coord.). Direitos sociais, fundamentos, judicialização, direitos sociais em espécie. Rio de Janeiro: Lumen Juris, 2008, p. 927-958.

MANUS, Pedro Paulo Teixeira. Direito do trabalho. 13. ed. São Paulo: Atlas, 2011.

MARTINS, Rui Décio. A técnica e o teletrabalho, violação dos direitos fundamentais. In: KIM, Richard Pae; BARROS, Sérgio Resende de; KOSAKA, Fausto Kozo Matsumoto (Coords.). Direitos fundamentais coletivos e difusos: questões sobre a fundamentalidade. São Paulo: Verbatim, 2012, p. 217-248.

MARTINS, Sergio Pinto. Direito do Trabalho. 30. ed. São Paulo: Atlas, 2014.

MORAES, Alexandre. Direito constitucional. 24. ed. São Paulo: Atlas, 2010.

NASCIMENTO, Amauri Mascaro. Curso de direito do trabalho. 28. ed. São Paulo: Saraiva, 2013.

PEREIRA, Leone. Pejotização: o trabalho como pessoa jurídica. São Paulo: Saraiva, 2013.

REMEDIO, Davi Pereira. O trabalho escravo no Brasil: amplitude do conceito em face da dignidade da pessoa humana. Leme: Habermann, 2017. 
REMEDIO, José Antonio; MARTINS, Ana Luísa Guimarães Fonseca. A admissibilidade do dano moral coletivo na justiça do trabalho. Conpedi Law Review, Braga, Portugal, v. 3, n. 2, p. 284-303, jul./dez. 2017.

ROSSO, Sadi Dal. O ardil da flexibilidade: os trabalhadores e a teoria do valor. São Paulo: Boitempo, 2017.

SILVA, José Afonso da. Curso de direito constitucional positivo. 37. ed. São Paulo: Malheiros, 2014.

TURCATO, Sandra; RODRIGUES, Rosualdo. PJ é artifício para sonegação de direitos. Revista da Associação Nacional dos Magistrados da Justiça do Trabalho - ANAMATRA. Ano XVIII, n. 55, p. 11-15, $2^{\circ}$ sem. 2008. 